\title{
A framework for preventing healthcare-associated infection in neonates and children in South Africa
}

\author{
A Dramowski, ${ }^{1} \mathrm{MB}$ ChB, DCH, FCPaed (SA), Cert Paed ID, PhD; M F Cotton, ${ }^{1} \mathrm{MB} \mathrm{ChB}, \mathrm{DCH}, \mathrm{FCPaed}(\mathrm{SA}), \mathrm{PhD}$; \\ A Whitelaw, ${ }^{2} \mathrm{MB}$ ChB, MSc, FCPath (SA) (Micro) \\ ${ }^{1}$ Department of Paediatrics and Child Health, Division of Paediatric Infectious Diseases, Faculty of Medicine and Health Sciences, \\ Stellenbosch University, Cape Town, South Africa \\ ${ }^{2}$ Department of Medical Microbiology, Faculty of Medicine and Health Sciences, Stellenbosch University and National Health Laboratory \\ Service (NHLS), Tygerberg Hospital, Cape Town, South Africa
}

Corresponding author: A Dramowski (dramowski@sun.ac.za)

Healthcare-associated infection (HAI) is a frequent and serious complication affecting 4 - $8 \%$ of hospitalised children and neonates in high-income countries. The burden of HAI in South African (SA) paediatric and neonatal wards is substantial but underappreciated, owing to a lack of HAI surveillance and reporting. Maternal and child health and infection prevention are priority areas for healthcare quality improvement in the National Core Standards programme. Despite increasing recognition in SA, infection prevention efforts targeting hospitalised children and neonates are hampered by health system, institutional and individual patient factors. To ensure safe healthcare delivery to children, a co-ordinated HAI prevention strategy should promote development of infection prevention norms and policies, education, patient safety advocacy, healthcare infrastructure, surveillance and research. We present a framework for SA to develop and expand HAI prevention in hospitalised neonates and children.

S Afr Med J 2017;107(3):192-195. DOI:10.7196/SAMJ.2017.v107i3.12035

Healthcare-associated infection (HAI) is the most frequent complication of hospitalisation, contributing to morbidity, excess mortality and increased healthcare costs. ${ }^{[1-3]}$ Although the neonatal and paediatric HAI burden is well described in high-income settings (4 - 8\% prevalence), ${ }^{[4,5]}$ the HAI burden in most African countries is unquantified. In a meta-analysis of HAI in low-middle-income countries (LMIC), the World Health Organization (WHO) identified only three studies of neonatal/paediatric HAI from Africa between 1995 and 2008 (none from South Africa (SA)). ${ }^{[6]}$ Prior and subsequent to the WHO meta-analysis, five publications have established HAI risk factors for hospitalised children in African settings, including malnutrition, ${ }^{[7-9]}$ prolonged hospital stay, ${ }^{[7,10]}$ use of indwelling devices, ${ }^{[9,11]}$ paediatric intensive care unit (PICU) admission, ${ }^{[9]}$ blood transfusion, ${ }^{[8,9]}$ young age, ${ }^{[7,10]}$ underlying comorbid diseases, HIV infection, and HIVexposed, uninfected status. ${ }^{[9]}$

\section{HAI epidemiology in hospitallised SA children and neonates}

The epidemiology of paediatric and neonatal HAI in SA is poorly documented. Literature describing neonatal HAI is extremely limited, reporting healthcare-associated bloodstream infection (HA-BSI) only; an HA-BSI incidence of 4/1 000 and 14/1 000 patient days was reported from two tertiary hospitals - in Cape Town and Johannesburg, respectively. ${ }^{[12,13]}$ Among paediatric inpatients in Cape Town, HA-BSI rates of 1.6/1 000 patient days were recorded, with excess mortality attributable to hospital- v. community-acquired BSI $(25 \%$ v. $16 \%){ }^{[14]}$ In 1987, prospective surveillance of two paediatric wards at Chris Hani Baragwanath Hospital, Johannesburg established an HAI prevalence of $14.3 \%$, with a predominance of gastrointestinal and respiratory tract infections. ${ }^{[7]}$ At the PICU at King Edward Hospital, Durban, SA, an HAI prevalence of $43 \%$ was reported in $1992 .{ }^{[10]}$ A 1-day point prevalence study of 2652 adults and children at six Gauteng hospitals established a pooled HAI prevalence of $9.7 \%$ for BSI, urinary tract, respiratory tract and surgical site infections. Children had higher HAI rates overall $(16.5 \%)$, and a greater prevalence of BSI and respiratory tract infections. ${ }^{[15,16]}$ Recent prospective clinical surveillance at Tygerberg Children's Hospital paediatric wards and the PICU documented an HAI prevalence of $24 \%$, with hospital-acquired pneumonia and HA-BSI predominating. HAI incidence density was highest in the PICU (94 v. 22/1 000 patient days in wards). ${ }^{[9]}$ PICU device-associated infection densities were double those reported from PICUs in other LMIC. ${ }^{[9,17]}$ Two-thirds of all in-patient mortality occurred in association with HAI, with crude mortality 6 -fold higher (7.4\%) than among HAI-unaffected hospitalisations. HAI-affected patients also had three-fold higher rates of hospital readmission within 30 days. HAI events incurred substantial direct costs (ZAR5.6 million) and an excess of 2275 hospitalisation days, 2365 antimicrobial days, and 3575 laboratory investigations in four wards over 6 months. ${ }^{[9]}$

\section{The changing landscape of HAI prevention in SA}

A national healthcare quality improvement programme launched in 2012 introduced annual facility audits to benchmark public and private institutions against 'national core standards (NCS) for healthcare establishments. ${ }^{[18]}$ In addition, the Office of Health Standards Compliance was established to guide NCS implementation and to act as a national healthcare licensing and accreditation body. Despite a renewed focus on infection prevention (IP) and HAI surveillance, data on HAI burden and epidemiology in SA are extremely limited. Although the development of IP standards is laudable, much greater resources and technical expertise (in healthcare epidemiology, IP and data management) are required 
to achieve data-driven improvement in HAI prevention services. Furthermore, implementation of HAI prevention in the SA healthcare context is complex, with multiple challenges to IP programmes at health system, institutional and patient level (Table 1).

\section{A proposed framework for neonatal and paediatric HAI prevention in SA}

Programmes to establish safe and high-quality delivery of healthcare to SA children require a co-ordinated HAI prevention strategy, informed by local surveillance and research. An important goal is to ensure that limited IP resources (at national, provincial and institutional level) are directed at the most common HAI events and populations at greatest risk. Prevention should employ a holistic, integrated approach incorporating policy development, IP education, patient safety advocacy, infrastructure development, surveillance and research. Table 2 outlines the major components and proposed content of a paediatric/neonatal HAI prevention framework for SA. Table 3 lists the key national, provincial and institutional partners for developing and implementing the proposed framework.

HAI prevention policies and guidelines Given their vulnerability to infection and the burden of communityacquired infection in hospitalised neonates and children, explicit recom- mendations on IP norms and standards are needed. Locally adapted IP guidelines and policies would assist paediatric and neonatal clinical managers to ensure implementation of best practices. One example where HAI prevention guidance is needed is for cleaning and disinfecting the healthcare environment, e.g. isolation rooms, incubators, and shared equipment. The risk of pathogen transmission and hospital outbreaks after ineffective cleaning of the patient environment is well recognised. ${ }^{[20-22]}$ Despite widespread implementation in high-income settings, few SA healthcare facilities have guidelines on environmental cleaning and even fewer perform routine assessment of cleaning adequacy. ${ }^{[23]}$ A study comparing methods for evaluation of paediatric isolation room terminal cleaning, identified fluorescent markers as an inexpensive option for cleaning assessment, which also allows for provision of immediate visual feedback to cleaning personnel. ${ }^{[23]}$ Other important topics include: staffing norms for IP and paediatric staff; management of patient isolation facilities; hand hygiene and personal protective equipment; HAI surveillance and reporting; outbreak investigation recommendations and reporting; antimicrobial usage and restriction; and staff vaccination.

\section{Education, training and advocacy for patient safety}

Surveys of SA healthcare workers and data from the first NCS audit show the need for improved in-service and undergraduate health

Table 1. Challenges to HAI prevention in hospitalised children and neonates ${ }^{\star}$

\begin{tabular}{lll}
\hline Health systems factors & Healthcare environment factors & Patient factors \\
\hline Competing health priorities & Overcrowding & Malnutrition \\
High burden of community-acquired & High patient-to-staff ratios & HIV exposure and HIV infection \\
infections & Lack of IP provisions and consumables & Prematurity \\
Few resources for IP implementation & Lack of isolation facilities & Chronic diseases \\
Lack of HAI surveillance programmes and & Ageing infrastructure & High device utilisation rates \\
reporting & Inadequate environmental cleaning & High antimicrobial usage \\
Lack of IP policies & Re-use and sharing of devices and equipment & \\
Lack of IP training for healthcare workers & Lack of a patient safety focus and institutional & \\
Lack of a co-ordinated research agenda for & culture & \\
HAI prevention & & \\
${ }^{*}$ Adapted from Rothe et al. ${ }^{[19]}$ & &
\end{tabular}

Table 2. Framework for HAI prevention in SA child health services

\begin{tabular}{ll}
\hline Component & Example of core content \\
\hline Policies and guidelines & $\begin{array}{l}\text { IP norms and standards for outpatient and inpatient settings, with a specific focus on paediatric and } \\
\text { neonatal populations; guideline documents for paediatric/neonatal wards and clinics, e.g. patient isolation } \\
\text { recommendations, guidelines on personal protective equipment use, environmental cleaning methods and } \\
\text { assessment, antimicrobial restriction policies }\end{array}$ \\
& A nations
\end{tabular}

Education, training and A national core curriculum on IP and HAI prevention for undergraduate health science and nursing students (with advocacy for patient safety additional neonatal/paediatric content); minimum topics/frequency of in-service training for all healthcare workers; standard in-hospital instructions for caregivers on basic IP control measures; national and provincial IP champions to lead education, advocacy and research; institutional buy-in from managers and departmental heads of department to prioritise safe care of children; collaboration within existing structures, e.g. IP and quality improvement committees

Provisions and infrastructure

Surveillance and research
Building norms for new and renovated neonatal and paediatric services, including consensus on a recommended ratio of single (isolation) to cohort beds, e.g. 1:2, and requirement for negative-pressure ventilation (with either natural or mechanical ventilation to achieve at least 12 air changes per hour); basic provisions for HAI prevention, e.g. soap, water, alcohol handrub, personal protective equipment

Develop recommendations for HAI surveillance methods, frequency and targets, e.g. HAI burden, spectrum, risk factors, distribution by ward/facility type and associated antimicrobial use; outbreak reporting; addition of HAI to existing morbidity and mortality registers; identification of key research questions to improve HAI implementation 
Table 3. Key partners for HAI prevention framework development and implementation

\begin{tabular}{ll}
\hline Level & Key stakeholders and partners \\
\hline National & The National Department of Health, Quality Assurance Directorate and \\
& Office of Health Standards Compliance \\
& South African Society for Paediatric Infectious Diseases \\
& South African Paediatric Association \\
& Infection Control Society of Southern Africa \\
& National Institute of Communicable Diseases (soon to be the National \\
& Public Health Institute of South Africa) \\
& United South African Neonatal Association (USANA) \\
& The Neonatal Nurses Association of South Africa (NNASA) \\
& The Society of Midwives of South Africa (SOMSA) \\
& The South African Antibiotic Stewardship Programme (SAASP) \\
& Best Care ... Always (BCA) campaign \\
& National Health Laboratory Service (NHLS) and other laboratories \\
& MRC Burden of Disease Unit \\
& Department of Health's provincial communicable disease teams \\
& Department of Health's provincial mother and child health (MCH) \\
& directorates \\
& District Health specialist teams (in obstetrics and paediatrics) \\
& University departments of paediatrics and child health, public health, \\
& infectious diseases, microbiology, virology and infection prevention \\
Facility medical and nursing managers & Infection prevention and control committees \\
Antimicrobial stewardship committees \\
Health and safety teams \\
Quality improvement structures \\
Primary healthcare networks (using existing structures for PMTCT, TB, EPI) \\
Provincial
\end{tabular}

MRC $=$ Medical Research Council; PMTCT $=$ prevention of mother-to-child transmission of HIV $\mathrm{EPI}=$ expanded programme on immunisation.

science training in IP. ${ }^{[24-27]}$ Development of harmonised IP curricula for all cadres of SA healthcare workers is needed, including recommendations on minimum training duration, core topics and competency evaluation. As risks and routes of infection transmission vary by population, additional content on paediatric and neonatal-specific risks would be needed, e.g. infant feeding. In a recent survey of 200 paediatric/neonatal medical and nursing staff at Tygerberg Children's Hospital, several important misconceptions about infection transmission routes and hand hygiene methods were identified. ${ }^{[26]}$ Although $48 \%$ of participants considered HAI to be inevitable, there was broad support for punitive measures for staff ignoring infection control recommendations (89\%) and for reporting of HAI episodes as adverse events (76\%). Multiple opportunities were identified for improvement, including poor uptake of annual influenza vaccination (25\%); low rates of N95 respirator fit-testing (28\%); and very high presenteeism among doctors (95\%), despite the risk of infection transmission to their patients. Participants required greater leadership and shared accountability for IP, acknowledging a weak institutional patient safety culture and climate. ${ }^{[26]}$ From this singlecentre study it is clear that there is scope for improved IP education for paediatric/neonatal staff. Moreover, identification of named 'infection prevention champions' in paediatric and neonatal departments who 'model' desired IP attitudes and behaviours, could assist with implementation of best practices and institutional culture change. Basic IP teaching packages and information packs for non-healthcare workers with regular patient contact (volunteers, visitors and caregivers) should also be developed.

\section{Provisions and infira- structure for IIP in paediatric/neonatal facillities}

In many high-income countries, paediatric wards are designed with single rooms and en-suite facilities to reduce the risk of infection transmission. Ironically, in resourcelimited settings, where the infection burden is highest, few or no patient isolation facilities exist. ${ }^{[19]}$ The IP indications for patient isolation are also likely to differ across SA.
At Tygerberg Children's Hospital, where isolation room demand consistently exceeded availability, airborne isolation for children with pulmonary TB was the predominant requirement (52\%) (with $26 \%$ of patients suffering from drug-resistant TB). ${ }^{[28]}$ To date, there are no data on availability of patient isolation facilities or negative-pressure ventilation rooms elsewhere in SA. In renovating and building new children's hospitals in SA, recommendations for the ratio of single to cohort beds, and numbers of airborne isolation beds (whether naturally or mechanically ventilated negative-pressure rooms), must be established. In addition, IP building norms for bed spacing, workflows, provision of handwash basins and sluice rooms, and guidance on other engineering and ventilation issues for neonatal/paediatric wards should be developed.

\section{HAI surveillance and research}

HAI surveillance is a key component of effective IP programmes and allows for comparison or 'benchmarking' between healthcare facilities. Despite the NCS requirement for HAI reporting since 2012, few SA healthcare facilities have the resources and expertise to perform comprehensive HAI surveillance. ${ }^{[29]}$ Futhermore, the lack of consensus on HAI surveillance methods in SA prevents direct comparison of data across healthcare facilities. The paucity of data on incidence, spectrum and local determinants of HAI also hampers development of appropriate IP interventions. Given these constraints and variable laboratory investigation testing rates, some feasible alternative surveillance options include use of routinely collected datasets (e.g. discharge coding, microbiology results or antibiotic prescriptions for HAI). A combination of laboratory and antimicrobial usage data at Tygerberg Children's Hospital achieved high sensitivity (85\%) and positive predictive values (97\%) for HAI determination, requiring substantially less time to collect/analyse than clinical surveillance data. ${ }^{[30]}$

Additional options to improve HAI surveillance and research in neonatal/paediatric wards include mandatory coding of HAI on patient discharge, transfer or death; and mandatory outbreak reporting and explicit inclusion of HAI in morbidity and mortality estimates (both institutional and provincial, e.g. the Perinatal and Child Healthcare Problem Identification Programmes). It is unlikely that a one-size-fits-all approach to paediatric HAI surveillance in SA will be successful. However, surveillance, even of only one or two parameters, must begin as 
soon as possible and be gradually expanded. Undoubtedly, development and maintenance of paediatric HAI surveillance and research networks will be challenging, but the data yielded on disease burden, spectrum, distribution, risk factors and outcome will be invaluable.

\section{Conclusion}

The lack of data on neonatal and paediatric HAI in SA has contributed to an underappreciation of the burden and impact of these infections by clinicians, healthcare managers, policymakers and the public. From the limited local data available, HAI causes considerable suffering, mortality and increased healthcare cost in all age groups. To ensure safe and high-quality healthcare for SA children, a framework for a nationally endorsed HAI prevention strategy is needed. The following should be addressed: IP policy and infrastructure development; healthcare worker education; patient safety advocacy; surveillance; and research. Key national, provincial and local stakeholder partners should be actively engaged to develop and implement HAI prevention programmes for hospitalised SA children and neonates.

Funding. Funding has been received from the South African Medical Research Council's Clinician Researcher Programme and the Discovery Foundation's Academic Fellowship Award.

1. Marchetti A, Rossiter R. Economic burden of healthcare-associated infection in US acute care hospitals: Societal perspective. J Med Econ 2013;16(12):1399-1404. http://dx.doi.org/10.3111/13696998.2013.842922

Societal perspective. J Med Econ 2013;16(12):1399-1404. http://dx.doi.org/10.3111/13696998.2013.842922
Zimlichman E, Henderson D, Tamir O, et al. Health care-associated infections: A meta-analysis of costs 2. Zimlichman E, Henderson D, Tamir O, et al. Health care-associated infections: A meta-analysis of costs
and financial impact on the US health care system. JAMA Intern Med 2013;173(22):2039-2046. http:// dx.doi.org/10.1001/jamainternmed.2013.9763

3. Januel JM, Harbarth S, Allard R, et al. Estimating attributable mortality due to nosocomial infections acquired in intensive care units. Infect Control Hosp Epidemiol 2010;31(4):388-394. http://dx.doi. org $/ 10.1086 / 650754$

4. Magill SS, Edwards JR, Bamberg W, et al. Emerging Infections Program Healthcare-Associated Infections and Antimicrobial Use Prevalence Survey Team. Multistate point-prevalence survey of health careassociated infections. N Engl J Med 2014:370(13):1198-1208. http://dx.doi.org/10.1056/nejmoal306801

5. European Centre for Disease Prevention and Control (ECDC). Point Prevalence Survey of Healthcare associated Infections and Antimicrobial Use in European Acute Care Hospitals. Stockholm. ECDC associated Infections and Antimicrobial Use in European Acute Care Hospitals. Stockholm: ECDC

20Survey.pdf (accessed 1 May 2016).

Allegranzi B, Bagheri Nejad S, Combescure C, et al. Burden of endemic health-care-associated infection in developing countries: Systematic review and meta-analysis. Lancet 2011;377(9761):228-241. http://
dx.doi.org/10.1016/s0140-6736(10)61458-4

dx.doi.org $/ 10$.

Cotton MF, Berkowitz FE, Berkowitz Z, et al. Nosocomial infections in black South African children. Pediatr Infect Dis J 1989;8(10):676-683. http://dx.doi.org/10.1097/00006454-198910000-00003

8. Aiken AM, Mturi N, Njuguna P, et al. Kilifi Bacteraemia Surveillance Group. Risk and causes of pediatric hospital-acquired bacteraemia in Kilifi District Hospital, Kenya: A prospective cohort study. Lancet 2011;378(9808):2021-2027. http://dx.doi.org/10.1016/s0140-6736(11)61622-x

9. Dramowski A, Whitelaw A, Cotton MF. Burden, spectrum and impact of healthcare-associated infection at a South African children's hospital. J Hosp Infect 2016;94(4):364-372. http://dx.doi.org/10.1016/j. jhin.2016.08.022
10. Bowen-Jones J, Wesley A, van den Ende J. Nosocomial colonisation and infection in a pediatric respiratory intensive care unit. S Afr Med J 1992;82(5):309-313.

11. Greco D, Magombe I. Hospital acquired infections in a large north Ugandan hospital. J Prev Med Hyg 2011:52(2):55-58.

12. Dramowski A, Madide A, Bekker A. Neonatal nosocomial bloodstream infections at a referral hospital Dramowski A, Madide A, Bekker A. Neonatal nosocomial bloodstream infections at a referral hospital
in a middle-income country: Burden, pathogens, antimicrobial resistance and mortality. Paediatr Int in a middle-income country: Burden, pathogens, antimicrobial resistance and mortally.

Child Health 2015;35(3):265-272. http://dx.doi.org/10.1179/2046905515y.0000000029
13. Ballot DE, Nana T, Sriruttan C, Cooper PA. Bacterial bloodstream infections in neonates in a developing country. ISRN Pediatr 2012;508512. http://dx.doi.org/10.5402/2012/508512

4. Dramowski A, Cotton MF, Rabie H, et al. Trends in pediatric bloodstream infections at a South African referral hospital. BMC Pediatr 2015;15:33. http://dx.doi.org/10.1186/s12887-015-0354-3

15. Duse AG. Surveillance of healthcare-associated infections (HCAIs) South Africa. http://www.cddep. org/sites/default/files/prof_adriano_duse-2_0.pdf (accessed 1 May 2016).

16. Durlach R, McIlvenny G, Newcombe RG, et al. Prevalence survey of healthcare-associated infections in Argentina; comparison with England, Wales, Northern Ireland and South Africa. J Hosp Infect 2012;80(3):217-223. http://dx.doi.org/10.1016/j.jhin.2011.12.001

17. Rosenthal VD, Jarvis WR, Jamulitrat S, et al., International Nosocomial Infection Control Members. Socioeconomic impact on device-associated infections in pediatric intensive care units of 16 limited-resource countries. Pediatr Crit Care Med 2012;3(4):399-406. http://dx.doi.org/10.1097/ pcc.0b013e318238b260

pcc.0b013e318238b260
18. National Department of Health. National Core Standards for Health Establishments in South

National Department of Health. National Core Standards for Health Establishments in South
Africa. Pretoria: NDoH, 2011. http://www.rhap.org.za/wp-content/uploads/2014/05/National-CoreAfrica. Pretoria: NDoH, 2011. http://www.

Standards-2011-1.pdf (accessed 3 May 2016).
19. Rothe C, Schlaich C, Thompson S. Healthcare-associated infections in Sub-Saharan Africa. J Hosp Infect 2013;85(4):257-267. http://dx.doi.org/10.1016/j.jhin.2013.09.008

20. Otter J, Yezli S, Salkeld J, French G. Evidence that contaminated surfaces contribute to the transmission of hospital pathogens and an overview of strategies to address contaminated surfaces in hospital settings. Am J Infect Control 2013;41(5):6-11. http://dx.doi.org/10.1016/j.ajic.2012.12.004

21. Kramer A, Schwebke I, Kampf G. How long do nosocomial pathogens persist on inanimate surfaces? A systematic review. BMC Infect Dis 2006:6:130. http://dx.doi.org/10.1186/1471-2334-6-130

22. Boyce J. Environmental contamination makes an important contribution to hospital infection. J Hosp Infect 2013;65:50-54. http://dx.doi.org/10.1016/s0195-6701(07)60015-2

23. Dramowski A, Whitelaw A, Cotton MF. Assessment of terminal cleaning in pediatric isolation rooms: Options for low-resource settings. Am J Infect Control 2016;44(12):1558-1564. http://dx.doi. rooms: Options for low-reso

24. Dramowski A, Marais F, Willems B, Mehtar S; the SURMEPI curriculum review working group. Does undergraduate teaching of infection prevention and control adequately equip graduates for
Dom Does undergraduate teaching of infection prevention and control adequately equip graduates for
medical practice? Afr J Health Professions Educ 2015;7(1 Suppl 1):105-110. http://dx.doi.org/10.7196/ medical pra
AJHPE. 500

25. Dramowski A, Marais F, Goliath C, Mehtar S. Impact of a quality improvement project to strengthen infection prevention and control training at rural healthcare facilities. Afr J Health Professions Educ 2015;7(1 Suppl 1):73-75. http://dx.doi.org/10.7196/AJHPE.499.

26. Dramowski A, Whitelaw A, Cotton MF. Healthcare-associated infections in children: Knowledge, attitudes and practice of paediatric healthcare providers at Tygerberg Hospital, Cape Town. Paediatr Int Child Health 2016;36(3):225-231. http://dx.doi.org/10.1080/20469047.2015.1109264

27. Health Systems Trust. National Health Care Facilities Baseline Audit: National summary report. Durban: Health Systems Trust, 2012. https://www.health-e.org.za/wp-content/uploads/2013/09/National-HealthFacilities-Audit.pdf (accessed 1 May 2016)

28. Dramowski A, Cotton MF, Whitelaw A. Utilization of paediatric isolation facilities in a TB-endemic setting. Antimicrob Resist Infect Control 2015;4:36. http://dx.doi.org/10.1186/s13756-015-0078-z

29. Visser A, Moore DP, Whitelaw A, et al. Part VII. GARP: Interventions. S Afr Med J 2011;101(8):587-595. Visser A, Moore DP, Whitelaw A, et al. Part VII. GARP: Inter
http://dx.doi.org/10.5402/2012/50851210.7196/SAMJ.5106

30. Dramowski A, Cotton MF, Whitelaw A. Surveillance of healthcare-associated infection in hospitalized South African children: Which method performs best? S Afr Med J 2017;107(1):56-63. http://dx.doi. org/10.7196/SAMJ.2017.v107i1.11431

Accepted 19 December 2016 